\title{
The Oceanographic Text Pattern: A Review AND COMPARISON OF INTRODUCTORY OCEANOGRAPHY TEXTS
}

\author{
By Richard W. Spinrad*
}

\begin{abstract}
$S$ YEARS AGO, when I first began to teach an undergraduate introductory oceanography course, I was faced with the issue of text selection. At the time the options were somewhat limited. It seems, however, that in the intervening years we've seen a bloom of new volumes. On the one hand this is terrific-it's a reflection of the growing interest in introducing college students to the field. On the other hand it makes text selection an even more daunting task. I'm reminded of my first trip to Starbuck's in Seattle several years ago when I was both delighted and overwhelmed by the sudden explosion of diversity offered to me in coffee, a commodity I had previously thought only came in two forms: a mug or a styrofoam cup.

Last year, Larry Atkinson approached the Associate Editors of Oceanography with a request for a review of the introductory oceanography texts currently available. In what I can now only determine was a spell of chronic masochism, I cheerfully volunteered for the task. In all honesty I had wanted to do such a review for my own course. so I welcomed (well. accepted) the job. With the assistance of Larry and Judi Rhodes, The Oceanogra-
\end{abstract}

Richard W. Spinrad, Consortium for Oceanographic Research and Education. 1755 Massachusetts Ave., NW, Suite 800, Washington. DC 20036-2101. USA.

* The opinions expressed in this article are solely those of the author, not that of TOS or CORE.

The texts reviewed here represent the publishers' and distributors ' response to a request for their most recent editors of oceanography texts. In some cases the reviewed volume may no longer be the most current volume available. Before making any text selection the reader is urged to contact the publisher for information on pending updates or revisions. phy Society collected seven current texts for review.

The texts that were reviewed are shown in Table 1.

This review was conducted with certain assumptions and "initial conditions." These are as follows.

- The review is based on the assumption that the text that will be used for a "300-level" introductory oceanography course. This assumption implies that the students (typically at the sophomore-junior level) will have had at least survey coursework in chemistry, biology, geology, physics, and mathematics. More specifically, I've assumed that the text will not be used in what some folks call the "Oceanography for Poets" courses!

- Each text should discuss some fundamental aspects of oceanography, as well as the current thinking on what might be called "leading edge" subjects. In this day and age it's just as important to teach concepts in primary productivity as it is to teach about marine biodiversity.

- Aesthetics and style count, especially in dealing with classrooms of students whose interest is often defined by the way in which material is presented. The reader might argue the point, but let's face it: if the text is difficult to read, or does not keep the reader's attention, it's not going to be very useful.

- No text will serve as the sole teaching tool in this kind of oceanography course. Any introductory oceanography course should include extensive use of videos, slides, classroom demonstrations, field trips, current journal articles, etc. As a result, the text should be a "launch pad" for get- ting to other resources. I've put a high premium on the value of the text as a reference for other materials. I've also limited the review to just the text as the students would buy it from the bookstore. There is clearly some variability in the nature and quality of supporting materials provided to instructors by the publishers, but that's not addressed here.

The review was conducted over the better part of a year and includes assessments of specifically selected topics, quantitative comparisons of particular metrics, and a subjective review of the style of each text.

\section{Subject Material}

Every text bears the effects of the interests/biases/background of the individual authors, so an effort was made to ensure that the topics selected for this review represented a reasonably broad definition of the field of oceanography. Having a master's in physical oceanography, a PhD in marine geology, and having done a lot of my research in bioöptical oceanography, I have a strong inclination toward teaching a broadly interdisciplinary course, and I feel a text should be equally broad. Consequently, in preparing this review I wanted to identify a spectrum of select topics for consideration. Obviously, the ideal review would include a thorough assessment of all aspects of the field. In the interests of time, and my own sanity, I selected several general and specific topics for review. The intent here is not to imply any excessive importance for these topics. Rather, I felt it was important that this review consider both the traditional and new subject matter that define the field of oceanography. 


\begin{tabular}{|c|c|c|c|c|}
\hline Author(s) & Title & Publisher & Copyright & ISBN \\
\hline Alison B. Duxbury \& Alyn C. Duxbury & Fundamentals of Oceanography (2nd Edition) & Wm. C. Brown & 1996 & $0-697-26671-0$ \\
\hline Tom Garrison & Oceanography-An Invitation to Marine Science (2nd Edition) & Wadsworth & 1996 & $0-531-25728-3$ \\
\hline M. Grant Gross \& Elizabeth Gross & Oceanography-A View of Eurth (7th Edition) & Prentice Hall & 1996 & $0-1,3-231788-5$ \\
\hline Dale E. Ingmanson \& William J. Wallace & Oceanography-An Introduction (5th Edition) & Wadsworth & 1995 & $0-534-24258-8$ \\
\hline Paul R. Pinet & Oceanography-An Introduction to the Planet Oceanus & West & 1992 & $0-314.77008 .9$ \\
\hline Keith Stowe & Exploring Ocean Science (2nd Edition) & John Wiley \& Sons & 1996 & $0-471-54376-4$ \\
\hline Harold V. Thurman & Introductory Oceanography (7th Edition) & Macmillan & 1994 & $0-02-420811-6$ \\
\hline
\end{tabular}

\section{General Subjects}

Two general topics were selected for side-by-side comparison. It's my firm conviction that there are several general topics that should be treated completely and accurately by any introductory oceanography text. I've chosen the topics of tides and primary production for this comparison.

\section{Tides}

Three A's, two B's, and two C's. Those are the grades for these texts on their treatment of tides. At the top of the list are Ingmanson and Wallace, Thurman, and Pinet.

Ingmanson and Wallace have given the reader more than might be necessary for a survey course. but the information will help those students wanting to overachieve. For example. before even discussing the forces involved in tides. Ingmanson and Wallace present a section on tidal periodicities that. although quite accurate, might quickly overload some undergraduates. Nonetheless. the authors" discussion of tidal forcing in equilibrium theory is excellent. The inclusion of examples of real tide charts and charts of tidal currents is a nice addition, but one wonders why the two data sets are not for the same site and time.

Thurman's presentation on tides is very thorough. I feel his treatment of forces is unnecessarily confusing, but he makes up for that with one of the best analyses of periodicities (via a very detailed breakout of tidal components). Of particular note in Thurman's text is the very nice special section on grunions and tides.

Pinet's treatment of tides is very good. He starts his discussion of forces at a simple level and builds to a more thorough and complex discussion. His chapter also has an interesting discussion on tidal measurement techniques. Pinet makes good use of graphics (especially his Fig. 8-15. showing theoretical and actual tides in two different restricted basins). Pinet, like Thurman, has his bit on grunions, but he goes one better to discuss the broader set of issues associated with tidal rhythms and biological organisms (including diatoms, crabs, and flatworms). One point worth noting Pinet is the only one of the texts without a picture of the Bay of Fundy (is that allowed?).

Good descriptions of tides, but not as good as the three listed above, are provided by Gross and Gross, and Stowe. Gross and Gross present the definitions of equilibrium theory and dynamical theory of tides, but neglect many of the details of the two. The reader is also not left with a good description of the multiple tidal components, and concepts such as cotidal lines are left untreated. I also felt that the details of whether a tide is semidiurnal, diurnal, or mixed are presented long before the general concepts of tidal forcing are presented. This could be distracting to some readers. Gross and Gross do, however, use some very good examples of variability in the nature of coastal and ocean tides. Stowe combines tides and waves into one chapter and provides excessively simplistic descriptions of tidal forces (perhaps using too many analogies such as the ball on the string, a bug crawling in a pan. etc.). Stowe relies heavily on cartoon descriptions. but his Figure 9.32 provides a good layout of the relative orbits and inclinations of the sun and moon. Stowe also provides a nice discussion of resonance as it relates to tidal range. as well as an excellent definition of the seven dominant tidal components.

Garrison, and Duxbury and Duxbury have treatments of tides that are below average. While Garrison provides a good definition of the forces and includes some nice graphics, he presents no discussion of equilibrium theory and dynamical theory. $\mathrm{He}$ also offers no basis for different regions having different tidal patterns (something most students are aware of and interested in). Duxbury and Duxbury's treatment of tides is too short, too dry, and incomplete. Their discussion begins with a droning series of definitions, and the presentation on forces is dry as sand. Duxbury and Duxbury's graphics are quite good, but the rest of the treatment is too perfunctory (e.g.. one paragraph on tidal currents, and nothing on open ocean tides or amphidromic systems).

\section{Priman Production}

The fundamental concepts of photosynthesis, respiration, gross production. and net production should be treated in these texts. Understandably, the detail of treatment can vary. but at the very least the students should get a broad presentation on the processes controlling primary production and the temporal and spatial distributions over a range of scales.

Pinet, Thurman, Gross and Gross, and Garrison provide the best discussions on this subject.

Pinet takes an ecosystem approach and includes some excellent supporting graphics addressing mechanisms and such important concepts as patchiness. $\mathrm{He}$ also provides a very nice discussion of terrestrial versus marine photosynthetic biomass. accompanied by an excellent description of cell growth. The role of bacteria is well addressed, using specific current research results. Similarly he includes the role of iron and other trace metals as micronutrients. A nice section on the use of Coastal Zone Color Scanner (CZCS) imagery rounds out Pinet's section very well. Only one confusing error in the legend of his plots for biomass and temperature correlation detracts from his overall treatment of primary production.

Thurman opens his treatment with his usual methodical discussion. this time on taxonomy. He provides a very fair treatment of controls and patterns (time and space) with good graphics, especially of productivity in temperate oceans (here 
he's got some excellent use of Advanced Very High Resolution Radiometer (AVHRR) and CZCS imagery off the U.S. east coast). Thurman also treats measurement techniques well and has a very nice treatment of biogeochemical cycling and the microbial loop.

Gross and Gross is one of the most readable of all of the texts on this subject. They take a strong ecosystem approach also. Their use of graphics to demonstrate the interplay of the pycnocline and the critical depth in defining the timing of a bloom is excellent. Some more graphics would help in their discussion of nutrient cycling, and their treatment of global patterns is limited to just four paragraphs with virtually no supporting data.

Garrison provides very good overall coverage of the topic. He starts with an excellent definition of primary production, but I was a bit confused as to why this section is separated from the discussion on photosynthesis found within an otherwise good chapter on "Life in the ocean." Nevertheless, his discussion of measurement techniques and a good discussion of global variability (I especially like the way he compares primary production in terms of "apples per square meter per year"!) make this a noteworthy treatment. Overall, the discussion is nicely done. albeit organized unusually.

Ingmanson and Wallace's treatment of primary production is rather frustrating. They seem to suffer from not seeing the forest for the trees (or is that the bloom for the cells?). Although they include much good information, the writeup is very dry, the discussion are too caught up in details, and the oceanographic aspects seem to be lost. For example. the discussion on photosynthesis dwells too heavily on concepts of acceptor molecules and energy transfer efficiencies, while making misrepresentative statements about the oceanography (e.g.. "Photosynthesis is restricted . . . [since] . . . sunlight penetrates only 40 or 50 meters into the sea."). The authors have a good discussion of the functional role of cell pigments and some excellent graphics of average annual productivity for a range of ecosystems, showing the role of open oceans compared to tropical rain forests (more people should see this!). However, their comparison of four ecosystems starts off with great promise (in terms of the treatment of the North Atlantic) but quickly turns into a subjective discussion with little more than a few pictures of biota. Ingmanson and Wallace also include very little on biogeochemistry and little or nothing on measurement techniques. Overall their treatment is spotty, dry, and suffers from loss of focus.

Stowe, and Duxbury and Duxbury are disappointing in their treatments of primary production. The Duxburys' discussion is quite cursory. The role of nutrients is described very briefly and is accompanied by graphics of only limited added value. Only three paragraphs are dedicated to measurement techniques (some CZCS data are shown, but there is no description of how the data are derived). There is also very little detail on temporal variability. Stowe's treatment of the subject suffers from oversimplicity and superficiality. Some concepts are described in frighteningly childish terms (e.g. ". . . The carbon atom by itself is quite reactive, so in order to be safely stored for later use, it is "placated" by attaching water molecules to it." Those readers with tendencies toward political correctness should feel assuaged with this attention to the issue of carbon abuse). Stowe's discussion of nutrient cycling is unacceptably brief, with virtually no supporting graphics. His treatment of measurement techniques is fair, not great (e.g., his statement that CZCS measures the top $2 \mathrm{~m}$ of the ocean conveys the right concept, but the wrong fact). Again, his description of global patterns of productivity is okay, but would be vastly improved with real data (easy to come by), rather than schematics.

\section{Focused Subjects}

Several more specific subjects were considered for review. The issue at hand here is the extent to which the text represents the state-of-the-science of oceanography. The subjects assessed were El Niño, hydrothermal vent biota, marine biodiversity, acoustic thermometry, and optics.

\section{El Niño/ENSO}

Every current oceanography text should have an extensive, up-to-date section(s) on El Niño, including our understanding of its mechanics, manifestations, and implications. Failure to include such is virtual blasphemy. Undergraduate students of the field must leave an introductory course with a good understanding of the topic, and a text that provides them with sufficient material for later reference.
Pinet provides one of the best discussions of El Niño (notwithstanding his confounding statement that "Because this is an oceanography textbook I am limiting the discussion of El Niño to the Pacific Ocean"). He presents a nice introduction to the subject by showing the evolution of sea surface temperature in the eastern Pacific. This is followed with an outstanding description of the processes associated with El Niño, and terrific data (temperature. tides, chlorophyll, and nutrients!). Pinet has also provided a very nice set of references, which, given the 1992 copyright of this text, are quite up-to-date.

Gross and Gross are unique in their "holistic" treatment of El Niño. Discussion of El Niño-Southern Oscillation (ENSO) is peppered throughout the text, as it should be. They make very nice use of satellite data (although some indication of temperature scales is called for here) and provide especially good discussions on post-El Niño effects, and on the value of ENSO forecasts for economic purposes. I particularly enjoyed their connections between ENSO and other processes, such as coral bleaching, fisheries, global climate change, and hurricane forecasts. Their references are minimal, however, and some of the discussion on relevant phenomena (e.g.. twin typhoons and Kelvin wave propagation) could benefit from additional graphics or data.

Thurman specifically highlights ENSO as a special feature in the text, thus giving it the attention that students need to see. His description of the process, and inclusion of some very nice quantitative graphics showing the onset and progression of the thermal signature (including side-by-side CZCS and AVHRR imagery) are excellent additions. Although there is disappointingly scant reference to the value and capabilities for forecasting El Niño, Thurman (like Gross and Gross) makes the connection to other phenomena very nicely.

Ingmanson and Wallace list the most recent El Niño as 1985-1986, suggesting that they have not studied the literature carefully (note that this is consistent with the statistics on their use of references). Their descriptions of the features of EI Niño, as well as the implications for global impact are fairly good. I note however that the graphics are mostly limited to conceptual, with little real data (Tropical Ocean-Global Atmosphere. TOGA, incidentally, is treated as a program just 
beginning). The whole section is limited to three pages, with minimal follow-up references.

Garrison suffers from similar problems as Ingmanson and Wallace. One upbeat point, however, is his use of satellite imagery (again, scales would help here). The discussion of global impact is insufficient but is consistent with Garrison's general treatment of ENSO as just another example of an "Exceptional Surface Current."

Stowe, who defines El Niño as an annual event, presents a very cursory and inaccurate representation of the phenomena. Statements such as "Plant life consumes the nutrients, so they arrive on the western sides (of the Pacific Ocean) relatively warm and lifeless" push the limits of scientific legitimacy. Once again. a lack of real data, a failure to discuss global impacts, and a total content of only four paragraphs makes this a disappointing section.

Duxbury and Duxbury consider El Niño as "a weather aberration that has importance to oceanography." As such it is given very cursory treatment in the text, with but a single graphic limited to one oversimplified temperature time series. Basically. El Niño is treated by Duxbury and Duxbury as just another airsea process. There is brief mention of global impact, forecasting ability, and economic consequences (mostly in terms of fisheries). This is a disappointment.

\section{Hydrothermal Vent Biota}

This is a tough subject. A lot of the material is only recently available. On the other hand, this is a critical element of any course in oceanography. The implications of these studies for our understanding of fundamental geology and biology, and the perplexing aspects of biology at such high temperatures and pressures raise this subject to paramount importance. Most authors included something on this subject. I note, however, that Duxbury and Duxbury include virtually nothing in this area.

Thurman is thorough in his treatment of hydrothermal vent biota. His section includes good graphics and a very nice discussion on the temperature limits and thermal sensing capabilities of these unique organisms.

Gross and Gross have some of the best graphics for this subject. They also include a nice discussion of chemosynthesis, but, again, the references could be stronger.
Stowe's treatment is minimal $\left(\frac{1}{2} \mathrm{col}\right.$ umn) with virtually no graphics and only minimal references. Pinet also has minimal graphics, but his treatment of the subject is quite thorough and reasonably accurate.

Ingmanson and Wallace have good anecdotal material. and they include an accurate definition of chemosynthesis as it is relevant to this issue. They include a nice section on colonization as well. The lack of references, however, may be a source of frustration. Garrison treats the issue in much the same fashion as Ingmanson and Wallace but provides an excellent set of references.

\section{Marine Biodiversity}

This topic was specifically selected for review for several reasons. Attention to this issue is quite recent (National Research Council, 1995), so its inclusion reflects the authors" sensitivities to "current events." This reviewer also feels that inclusion of this topic in any oceanography text will help to raise students' awareness of an important and timely issue. Finally, marine biodiversity is a tough subject to discuss at an introductory undergraduate level, so it represents a challenge for inclusion in any text.

For the same reasons as specified above, in fact, four of the seven texts do not even include the topic (regardless of whether one calls it "marine biodiversity." "diversity," "biodiversity," or "species diversity").

Gross and Gross provide the best discussion of this subject. Most importantly they take the topic "head on" and indicate up front that it is a tough issue to define. At the very least they provide enough discussion to raise the awareness of the student. Users of Gross and Gross would be well-advised to utilize this as a starting point for a more detailed lecture on the subject.

Garrison's treatment of the subject is minimal and limited to comparisons of benthic diversity to surface diversity - not really the issue at hand. Similarly Pinet shows species diversity in different marine environments and peppers the concept throughout the text, but also does not deal with the question of what is the extent of, or trends in, marine biodiversity.

\section{Acoustic Thermometry}

This topic was included for consideration by virtue of its relative newness and considerable visibility. Interestingly, only three of the seven texts deal with the issue at all (Stowe doesn't even include a reference to either "acoustics" or "sound" in his index, and I could only identify one paragraph discussing echo sounding in that text). The three that discuss acoustic thermometry in any way are Thurman, Gross and Gross, and Garrison.

Thurman provides an excellent treatment of the subject. Helpful schematic graphics and a good reference are provided in his text. Gross and Gross provide scant reference to the capability for acoustic thermometry, but they include a very nice "Theme of the Times" summary of the Heard Island experiment. Garrison's description is quite fair, accurate, and complete, with good graphics. I should also note, in passing, while discussing acoustics Garrison provides a nice description of the WHALES 93 experiment for tracking marine mammals using the Navy Sound Surveillance System (SOSUS) arrays.

\section{Optics/Light}

My own bias for subjects optical is revealed in my insistence that this field be covered in any introductory oceanography text. In the last decade we've seen an explosion in the understanding and application of radiative transfer theory to any number of oceanographic problems. The understanding has been translated into quantitative measurement capabilities in physical, biological, chemical. and geological oceanography. Upon reflection (pun intended) one must conclude that an introductory oceanography text is less than illuminating (pun intended) if it does not include a healthy treatment of the field.

In this regard most of the texts are disappointing. Pinet, Duxbury and Duxbury, Thurman, and Stowe treat the subject quite superficially (Pinet and Stowe even go so far as to have no references on the subject). Garrison's treatment of the field includes a good set of references. He also is somewhat repetitive in his definition of the concept of a photic zone, but this can be a good way of getting the point across. Ingmanson and Wallace reads like a physics text and puts too much attention on the concept of refractive index (versus, say, attenuation, scattering, and absorption). Also, while being more thorough than the others, Ingmanson and Wallace is also misleading in sections (e.g., statements that it is mud, vice dissolved matter. which can give sea water a 
yellow tinge, or that "light intensity decreases steadily" with depth), but this text has the best set of references of all on the subject. Gross and Gross is the only text that discusses the important role of dissolved materials in defining ocean color. While their text also suffers from lack of references, and is a bit too anecdotal on this subject. it has an excellent description of the influence of depth-dependent spectral variability on biological pigmentation.

\section{References Used in the Textbook}

One key metric included in this review is the way references are used in each text. References are like good friends: we all should have plenty of them, with a good mixture of new ones and old stand-by's. It's also my feeling that the references. on average, should be relatively recent. Clearly, the age of the reference is only one measure. As important is the significance of the reference, as well as its availability (it does no good to have a plethora of citations from the Lower Mongolian Journal of Applied Magnetohydrodynamics). In conducting the following assessment I analyzed five chapters of each text. To ensure a reasonably fair, consistent, and diverse sample. I selected the first and last chapters (which typically include some of the oldest and newest references) and three randomly selected additional chapters. The results of the study on references are found in Table 2.

\section{Special Features-What's Different?}

Each of the texts tends to follow a general pattern of chapters as follows:

1. "In the beginning there was the earth . . ." and some general history of oceanography

2. Plate tectonics

3. Geology

4. Chemistry and Physics

5. Biology

6. Policy-type issues.
Above and beyond this very coarse (and overly general) description of the structure of the texts each of the authors has imposed certain stylistic additions. changes, and special features. The following is a synopsis of these different aspects, alphabetically by author.

\section{Duxbury and Duxbury}

Each chapter includes a good statement of "learning objectives" up front and an adequate summary of the material at the end. There are also helpful "boxes" that call out key questions in each section. The references and additional readings at the end of each chapter are described as "nontechnical" by the authors, but include several from Science. These reading materials appear to be adequate. The authors have chosen to include six "Items of Interest" in the text (these are "Archaeology," "Robotic devices," "Biological invaders," "Clouds," "Marine birds," and "Current patterns traced by following bathtub toys and tennis shoes"). With the exception of the item on marine birds, which seems out of place in this text (by virtue of reading more like an Audubon guide), these are all good. The item on clouds is excellent in terms of its laying the foundation for the role of clouds in modern modeling efforts. I was. however, left with the question of why only six items of interest. Shouldn't there be such an item for each of the chapters? The three appendices in the text deal with determining latitude and longitude, biological taxonomy, and scientific notation. Given the diversity of appendices in several of the other texts reviewed, I consider the Duxburys' appendices minimal.

\section{Garrison}

This text has lots of aesthetically pleasing graphics (photos, painting, drawings, charts, satellite images, etc.). The text is also very readable. Garrison has chosen to start his chapters with a short

Table 2

Reference study results

\begin{tabular}{lcccc}
\hline \multicolumn{1}{c}{ Text } & $\begin{array}{c}\text { Oldest } \\
\text { Reference }\end{array}$ & $\begin{array}{c}\text { Newest } \\
\text { Reference }\end{array}$ & $\begin{array}{c}\text { Mean } \\
\text { Ycar }\end{array}$ & $\begin{array}{c}\text { Mean Number } \\
\text { Per Chapter }\end{array}$ \\
\hline Duxbury \& Duxbury & 1980 & 1994 & 1989 & 11 \\
Garrison & 1929 & 1995 & 1983 & 39 \\
Gross \& Gross & 1951 & 1995 & 1982 & 8 \\
Ingmanson \& Wallace & 1922 & 1992 & 1976 & 20 \\
Pinet & 1953 & 1988 & 1977 & 22 \\
Stowe & 1953 & 1994 & 1987 & 13 \\
Thurman & 1859 & 1993 & 1980 & 24 \\
\hline
\end{tabular}

vignette up front (nice attention-getter). Key words are highlighted in the text and tabulated at the end of the chapter. Each chapter includes a set of questions and answers. I was confused about the value of these, because most of the material that they cover could just as easily be included as a standard part of the text. There is a separate, and generally good. set of study questions included at the end of the chapter. The boxes in the chapters provide good examples of commentaries and some quirky bits that might keep students' attention (one exception that doesn't belong is the cheaply entertaining box on sea monsters). Most of the references cited are easily accessible. Garrison includes as the standard appendices the (usual) treatment of measurements/conversion, geological time, latitude/longitude/navigation, and taxonomy, but adds a good appendix on mapping and charting. The inclusion of an appendix on jobs in marine science is noble, but provides some strange guidance ("Certification as a SCUBA diver is almost mandatory.").

\section{Gross and Gross}

This text starts off with the clear statement that the emphasis is on applications of ocean science that benefit society and pervasive themes (earth systems, time/ space scales. and system stability): you gotta love it! The text includes a very impressive list of reviewers and contributors (including L. Atkins at Old Dominion University, undoubtedly the father of the editor of this fine magazine). Graphics are very attractive. numerous and helpful. with excellent explanations overall. The text is also written in a very readable fashion. Each chapter includes media boxes-Themes of the Times. from the New York Times. This is a nice feature that could be embellished with reference to specific articles from the NY Times. Chapters also include "regular" boxes on other material. These are not as good, and appear to be the pieces that the Grosses had trouble placing otherwise (e.g., Columbus. underwater archaeology. and the Gaia hypothesis). Chapters also include key terms and study questions and "critical thinking" questions, intended to integrate material. These "critical thinking" questions (e.g.. "Why are there so few tidal power plants?". "Which parts of the open-ocean ecosystem are most vulnerable to increased levels of UV radiation caused by the ozone hole?") deserve special note, because 
they are an outstanding addition to the text (in fact, I would recommend their use as topics for term papers). The authors are to be complimented for their creativity and insight in including these. The appendices to the Grosses' text are probably the best of all the texts reviewed here. They include the usual taxonomy, geological time scales, conversion factors, and a glossary. In addition, an appendix on "Useful data about earth and its oceans" is a great quick reference for students. The appendix on "Presenting Data" is a critical primer for undergraduates and includes the important issues, such as map projections and vertical exaggeration, specific to the ocean sciences. The appendix on "Careers in Oceanography" treats the issue of "emerging areas" very nicely. Finally, the appendix on "People in Oceanography" is a nice touch, but it should be more comprehensive.

\section{Ingmanson and Wallace}

This text is the stripped down, bare bones, plain vanilla. come-as-you-are variety. No frills here. There are lots of graphics, but they're all black and white. The chapters have no questions, no summaries, just a good set of references. Ingmanson and Wallace included an impressive list of reviewers (including Tom Garrison, the author of one of the other texts reviewed). One exclusive in this text is the special treatment of polar oceanography. Although this makes for interesting reading, the neophyte oceanographer might have no sense of why this topic is called out for such special attention. The authors could justify this better. The appendices in this volume are generally pretty standard stuff: latitude/longitude overview, scientific notation, constants and equations, a summary of some physical laws (helpful), geological time scale, taxonomy, and a very good glossary (especially with its addition of supplemental references). Somewhat perplexing is the addition of an appendix on the Coriolis effect (why isn't this fundamental oceanographic concept included in the body of the text?), and a set of charts of the U.S. coastline, excluding Alaska and Hawaii.

\section{Pinet}

The author put a lot of thought into the organization of this text. It has three parts. The first section is an historical perspective (including the history of the earth), with an exquisitely engaging imaginary trek across the floor of the Atlantic-this should be required reading for any introductory oceanography class! The second section is described as the "heart" of the text; it includes the basic geology, chemistry. physics, and biology. A nice addition to this section is the chapter on the earth as a whole, including discussions of the carbon cycle, air-sea interaction, etc. The final section is what Pinet describes as "case histories," a set of specific studies on coastal oceans, the continental shelf, the open ocean, and gulfs and seas. This organizational structure is unique and is an excellent approach. In general the text is eloquently written (it better be, given its poetic title!). Graphics are good, not great; there is minimal use of color and too much is conceptual. The use of remote sensing is unimpressive. Each chapter includes a preview. which ties the chapters together well, and many, many keywords (perhaps too many; I counted an average of 75-80 per chapter!). One frustration I had with this text is the relatively large number of typographical mistakes. Chapters include boxes that are well written but their raison d'etre is ill posed. Key concepts at the end of each chapter serve as an outstanding bulletized summary. The review and discussion questions are slightly regurgitative in nature and the selected readings are mostly composed of citations from "Oceanus," "Sea Frontiers," and "Scientific American." The appendices in Pinet's text are adequate, not noteworthy; the appendix dealing with "Important Chemical Reactions" should be part of the body of the text.

\section{Stowe}

Stylistically this text has much going for it. The graphics are very attractive and represent a good mix of photography, stylized data, and conceptual drawings. The author has few "bells and whistles" (in fact, the preface states that there are no separate boxes to interrupt the presentation), but has included a special blue icon to tag topics of special societal and environmental concerns (just in case the students miss the point that something is a special concern!). Each chapter includes an outline, highlighted quotes, key terms, and a summary. The study questions are not very helpful. but the "Critical Thinking Questions" are excellent.
These questions actually force the students to think/analyze/synthesize (for example, "If gravity were stronger would waves travel faster or slower? Why?"). Stowe's references are good and easily accessible. The appendices, or rather appendix. is inadequate: all that's provides here is a glossary.

\section{Thurnan}

What's different here is that the au thor has chosen to emphasize how technology increases our ability to study process. He does this by making sure to include an aspect of technology in each chapter. The author has also put some emphasis on the role of large scale programs, and the impact of human activities. This makes for a timely and fair treatment of issues in ocean science. Generally the graphics are quite nice, including good use of remotely sensed imagery and some dramatic photographs. Each chapter includes a summary up front, key words (cross-referenced with page numbers at the end of the chapter), and a summary (not particularly helpful). Special topics are identified for each chapter (e.g. meteoric impact and the $\mathrm{K}$ $\mathrm{T}$ boundary, the Fastnet disaster, etc.) and are all very well done and very appropriate to the material at hand. The questions at the end of each chapter are very dry. The references are treated uniquely in that they are separated as standard references in the technical literature (including the major scientific journals such as $J G R$, Science, Nature, DSR, and $J P R$ ), plus "suggested reading" exclusively from "Sea Frontiers" and "Scientific American." This is a good way of treating references. Once again. Thurman contains a set of traditional appendices (latitude/longitude, scientific notation. etc.). He also includes, as an appendix, a calculation of how the mantle could serve as a source of ocean water; this should be in the main text. Another appendix on roots, prefixes and suffixes seems a bit quirky and esoteric. A detailed glossary, a phylogenetic tree, and a periodic table round out the list of appended materials.

\section{Summary}

Overall, the texts shake out as shown in Table 3.

\section{Recommendations}

Any instructor will have his or her own criteria for text selection, but this re- 


\begin{tabular}{|c|c|c|c|c|c|c|c|}
\hline & $\begin{array}{c}\text { Duxbury \& } \\
\text { Duxbury }\end{array}$ & Garrison & $\begin{array}{c}\text { Gross \& } \\
\text { Gross }\end{array}$ & $\begin{array}{l}\text { Ingmanson and } \\
\text { Wallace }\end{array}$ & Pinet & Stowe & Thurman \\
\hline Tides & ma & & & & & & \\
\hline Primary Productio & & & & & & & \\
\hline El Niño & & & & & & & \\
\hline $\begin{array}{c}\text { Hydrothermal Ven } \\
\text { Biota }\end{array}$ & & & & & & & \\
\hline Biodiversity & $\varnothing$ & & & $\varnothing$ & & $\varnothing$ & \\
\hline $\begin{array}{c}\text { Acoustic } \\
\text { Thermometry }\end{array}$ & $\varnothing$ & & & $\varnothing$ & $\varnothing$ & $\varnothing$ & \\
\hline Optics & & & & & & & \\
\hline References & & & & & & & \\
\hline Style & & & & & & & \\
\hline
\end{tabular}

Legend:

Below Average won Average

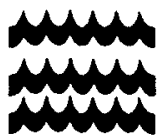

Above Average $\emptyset$ Not Included view has been intended to use a wide range of metrics. thus assisting each individual in making that decision. My interpretation of the results of this review is that there are three classes of texts: those that will serve the needs of almost any introductory oceanography course, those that might be fine for a short course or a class of limited scope, and. finally, those that really don't serve the needs of teaching any college level oceanography course.

The texts of Stowe and Duxbury and Duxbury fall into the last category. In virtually every category of review these textbooks failed to pass muster. The material tends to be dealt with too superficially (if at all) and the supporting materials are insufficient. It's my sense that an instructor would be buying problems by using these texts. Students would not get a good sense of the field, and the professor would be forced to double or triple the students' time. money, and effort, in terms of procuring additional materials.

Ingmanson and Wallace provide a good, albeit not great, text. This text suffers mostly from the stylistic standpoint. Nevertheless, the material is adequate and fairly treated overall. Some of the more modern subjects are not dealt with at all, but the traditional oceanographic material is adequate. When used in conjunction with other study materials, this text provides a perfectly good overview of the field and is recommended for such venues as a short course, or a seminar series.

The text by Garrison is also generally good, but is prone to spotty coverage. Although it is an attractive and readable volume, the treatment of tides, for example, is disturbing and may be symptomatic of additional deficiencies. Instructors intent on using Garrison's text are 
strongly advised to compare their curriculum closely with the text for compatibility.

Clearly the top texts in this review are those by Gross and Gross, Pinet, and Thurman. Gross and Gross cover all of the material, both traditional and modern, in an adequately complete manner. The special touches identified above make this text especially valuable. Users of Gross and Gross will want to provide their own list of additional references for students. Thurman is also a strong text and works well for the traditional approach to teaching oceanography. Supplements for some of the newest research findings will help when using Thurman. Finally, Pinet is an excellent text, which lends itself nicely to a newer approach to teaching the subject. Because Pinet is the oldest of the texts, it also will need supplements from the latest literature.

Whichever text you choose, enjoy your opportunity to teach the subject. Meanwhile, I'm going out to get that decaf double mocha latte I've been waiting for!

\section{Acknowledgements}

I am very grateful to Rich Stephens for his assistance in this review. I also thank Larry Atkinson, Judi Rhodes, and Anne West-Valle for their patience with me and my gradual progress in this sisyphean task.

\section{Reference}

National Research Council. 1995: Understanding Marine Biodiversity; National Academy Press, 114 pp. ISBN 0-309-05225-4. 